\title{
Passive Tracer Visualization to Simulate Aerodynamic Virus Transport in Noninvasive Respiratory Support Methods
}

\author{
Rutger Hendrik Johan Hebbink ${ }^{a}$ Judith Elshof ${ }^{b, c}$ Steven Wanrooij ${ }^{a}$ \\ Walter Lette $^{a} \quad$ Mariëtte Lokate $^{d} \quad$ Cornelis Henricus Venner $^{a} \quad$ M.L. Duiverman ${ }^{b, c}$ \\ Rob Hagmeijer ${ }^{a}$
}

\begin{abstract}
aEngineering Fluid Dynamics, University of Twente, Enschede, The Netherlands; ${ }^{b}$ Department of Pulmonary Diseases/Home Mechanical Ventilation, University of Groningen, University Medical Center Groningen, Groningen, The Netherlands; ' ${ }^{c}$ roningen Research Institute for Asthma and COPD (GRIAC), University of Groningen, Groningen, The Netherlands; ${ }^{\mathrm{d} D e p a r t m e n t}$ of Medical Microbiology, University of Groningen, University Medical Center Groningen, Groningen, The Netherlands
\end{abstract}

\section{Keywords}

Droplet transmission of infectious disease $\cdot$ Respiratory

care $\cdot$ Viral particles $\cdot$ SARS-CoV-2 $\cdot$ COVID-19

\begin{abstract}
Background: Various forms of noninvasive respiratory support methods are used in the treatment of hypoxemic COVID-19 patients, but limited data are available about the corresponding respiratory droplet dispersion. Objectives: The aim of this study was to estimate the potential spread of infectious diseases for a broad selection of oxygen and respiratory support methods by revealing the therapy-induced aerodynamics and respiratory droplet dispersion. Methods: The exhaled air-smoke plume from a 3D-printed upper airway geometry was visualized by recording light reflection during simulated spontaneous breathing, standard oxygen mask application, nasal high-flow therapy (NHFT), continuous positive airway pressure (CPAP), and bilevel positive air-
\end{abstract}

way pressure (BiPAP). The dispersion of $100 \mu \mathrm{m}$ particles was estimated from the initial velocity of exhaled air and the theoretical terminal velocity. Results: Estimated droplet dispersion was $16 \mathrm{~cm}$ for unassisted breathing, $10 \mathrm{~cm}$ for Venturi masks, $13 \mathrm{~cm}$ for the nebulizer, and $14 \mathrm{~cm}$ for the nonrebreathing mask. Estimated droplet spread increased up to $34 \mathrm{~cm}$ in NHFT, $57 \mathrm{~cm}$ in BiPAP, and $69 \mathrm{~cm}$ in CPAP. A nonsurgical face mask over the NHFT interface reduced estimated droplet dispersion. Conclusions: During NHFT and CPAP/BiPAP with vented masks, extensive jets with relatively high jet velocities were observed, indicating increased droplet spread and an increased risk of droplet-driven virus transmission. For the Venturi masks, a nonrebreathing mask, and a nebulizer, estimated jet velocities are comparable to unassisted breathing. Aerosols are transported unboundedly in all these unfiltered therapies. The adequate use of protective measures is of vital importance when using noninvasive unfiltered therapies in infectious respiratory diseases.

(c) 2021 S. Karger AG, Base karger@karger.com www.karger.com/res
(C) 2021 S. Karger AG, Basel

Karger!
Correspondence to:

Rutger Hendrik Johan Hebbink, r.h.j.hebbink@utwente.nl 


\section{Introduction}

Since the outbreak in December 2019, SARS-CoV-2 has spread over the world. SARS-CoV-2 causes the infectious disease COVID-19. Although most people recover from COVID-19 without needing hospital treatment, around $26-33 \%$ of the patients admitted to the hospital experience respiratory failure needing some form of respiratory assistance $[1,2]$. As COVID- 19 primarily causes hypoxemic respiratory failure, the first step is to administer oxygen (via nasal prongs, Venturi masks [3], or nonrebreathing masks [4]). In the case that this is insufficient, several noninvasive respiratory support options are available such as nasal high-flow therapy (NHFT), continuous positive airway pressure (CPAP), and bilevel positive airway pressure (BiPAP) [5].

Concerningly, up to $29 \%$ of the health care workers got infected during the COVID-19 pandemic [6]. Respiratory viruses, such as SARS-CoV-2 [7] and Influenza [8], are spread through respiratory droplets and aerosols. Since the above-mentioned respiratory support methods do not filter exhaled air, the high air flows applied may increase the spread of viral particles present in the exhaled air of an infectious person, possibly causing new infections. During the first wave of the COVID-19 pandemic, this has led to reluctance applying potential effective noninvasive respiratory support measures, as there was fear that health care workers might become infected when applying these therapies [9]. Although some papers [10-12] have attempted to investigate viral spread with noninvasive respiratory support measures, these studies have limitations due to the methods used. Most studies did not take into account differential particle size, and this largely influences the behavior of the particles after being expelled.

Bourouiba [13] showed that a human sneeze produces a turbulent cloud in which, due to low evaporation rates, droplets can travel up to $8 \mathrm{~m}$. Exhaled air of patients contains droplets with diameters typically ranging from 0.1 $\mu \mathrm{m}$ to $1 \mathrm{~mm}[14,15]$, and all sizes may cause virus transmission [7]. During respiratory support, exhaled air escapes from the mask, nose, or mouth of a patient in the form of an exhalation jet that is shaped by the therapeutic device [16]. The droplets in the jet follow very different trajectories depending on their size: large droplets fly ballistically as if there were no air present, but small droplets (aerosols) are perfectly carried along by the airflow. Intermediate droplets fly semiballistically, influenced by the airflow but not completely carried along with it.

A comprehensive way of ranking droplets in ballistic behavior is to compare their terminal vertical velocity to the air velocity encountered during respiration therapies, which is in the order of $1 \mathrm{~m} / \mathrm{s}$. Based on the theory presented by Flagan and Seinfeld [17], the vertical fall speed approximately scales quadratically with the droplet diameter: in standard air $\left(1 \mathrm{bar}, 21^{\circ} \mathrm{C}\right), 1 \mathrm{~mm}$ water droplets reach $4 \mathrm{~m} / \mathrm{s}, 10 \mu \mathrm{m}$ droplets reach approximately $3 \mathrm{~mm} / \mathrm{s}$, and $100 \mathrm{~nm}$ droplets (virus size) reach only $0.3 \mu \mathrm{m} / \mathrm{s}$. Larger droplets therefore tend to fall out of the jet within limited reach, whereas aerosols may stay airborne for hours. Due to evaporation, isolated droplets $<100 \mu \mathrm{m}$ are likely to form droplet nuclei (aerosols) before settling [18]. However, it was demonstrated that sneezes and coughs are primarily made of a multiphase turbulent gas cloud, in which evaporation rates are low and the range of both small and large droplets is extended $[13,19]$.

Unfortunately, although NIV, CPAP, and NHFT are recognized to be aerosol-generating procedures, there are only limited data available about the actual dispersion of particles during noninvasive respiratory support methods. Two studies determined the visible dispersion distance of exhaled air around oxygen masks [10] and during NHFT and CPAP [12], based on smoke visualization. However, because both studies used different setups, the visualization results of the different therapies cannot be well compared. More importantly, the visible dispersion distance of exhaled smoke is not an adequate tool to measure the dispersion distance of droplets or aerosols exhaled by patients: it only indicates the flow field of the air to a certain extent.

Smoke particles, such as aerosols, qualify as passive tracers: they follow the airflow almost perfectly. So, by visualizing smoke, one visualizes the motion of the air. A crucial point in smoke visualization is the caution needed when interpreting the resulting images. Because fresh air mixes with the smoke over time, the smoke becomes less and less visible. This reduced visibility should not be confused with the absence of smoke particles or aerosols: it only means that their concentration is low. Since viruses can remain viable in aerosols for hours [20], the visible extent of smoke particles should not be taken as indicative for virus spread through aerosols, although a certain amount is necessary to cause an infection.

Despite this reservation, smoke visualization can well be used to indicate the flow field up to some extent and to qualitatively indicate jet velocity and aerosol concentration. In this study, the therapy-induced aerodynamics of a broad selection of oxygen and respiratory support methods are revealed by performing a passive tracer study using smoke visualization. The flow fields are used to estimate the jet velocities and corresponding fixed-size 
droplet dispersion based on the terminal velocity. Because a single setup is used in all therapies, a qualitative comparison of differences in possible viral spread during the therapies can be made.

\section{Materials and Methods}

The therapy-induced aerodynamics were visualized by smoke particles. A schematic overview of the setup is shown in Figure 1. A 3D-printed upper airway geometry was used, based on a CT scan of a male adult obtained from Ref. [21] and modified with the author's permission. The geometry was placed at the border of an approximately $80 \mathrm{~cm}$ high table to avoid early jet impingement. At the backside of the 3D-printed model, just downstream of the point where the 2 nasal cavities merge, a lung simulator was connected to simulate healthy tidal breathing with a tidal volume of $475 \mathrm{~mL}$ and a respiratory rate of $15 / \mathrm{min}$. The lung simulator consisted of a pneumatic cylinder (P1D-S050MS-0320; Parker, Cleveland, OH, USA) driven by a rigidly connected linear motor (PS0137Sx120F-HP-N; LinMot, Spreitenbach, Switzerland). Smoke was generated in a reservoir between the lung and the head, using Miniax KS smoke patterns (Björnax AB, Nora, Sweden), which produced particles between 0.3 and $2.5 \mu \mathrm{m}$.

Different therapies were applied to the setup: unassisted breathing, NHFT (via the Airvo 2; Fisher and Paykel Healthcare, Auckland, New Zealand), CPAP (via the BiPAP A30 in CPAP mode; Philips Respironics, Murrysville, PA, USA), BiPAP (via the BiPAP A30; Philips Respironics, Murrysville, PA, USA), Venturi masks (EcoLite; Intersurgical Ltd., Berkshire, UK), a nebulizer (Cirrus 2 with EcoLite mask; Intersurgical Ltd., Berkshire, UK), and a nonrebreathing oxygen mask (EcoLite adult high-concentration mask; Intersurgical Ltd, Berkshire, UK). To prevent air leakage along the masks during CPAP and BiPAP, the air leaks were sealed using silicone sealant. CPAP and BiPAP were tested with 2 setups: with a vented oronasal mask (Simplus full face mask; Fisher and Paykel Healthcare, Auckland, New Zealand) and also with a nonvented mask (FlexiFit 431 full face mask; Fisher and Paykel Healthcare, Auckland, New Zealand) with a whisper swivel (Whisper Swivel II Exhalation Port; Respironics Inc., Murrysville, PA, USA). In a clinical setting, a filter would be placed before the whisper swivel, but this filter was removed in the experimental setup because the smoke particles could not pass through it. Finally, both unassisted breathing and NHFT were tested with a nonsurgical face mask attached to the 3D-printed model.

Two cameras, for frontal and top views, recorded the light reflection from the exhaled smoke. The movie frames were postprocessed by subtracting a reference frame without smoke, and by increasing the contrast. In this way, locations that changed compared to the reference frame appear in white, whereas locations that did not change appear in black. To ensure that the 3D-printed head was clearly visible in the movies, its image was copied from the unprocessed frames.

The reach of $100 \mu \mathrm{m}$ (virus-carrying) droplets was estimated from the initial velocity of the exhaled air and the theoretically known terminal velocity of $25 \mathrm{~cm} / \mathrm{s}$ [17]. Isolated droplets were considered, and evaporation was neglected as $100 \mu \mathrm{m}$ droplets settle sooner than they evaporate [18]. The velocity was estimated by combining the 2 camera views, and by determining the distance

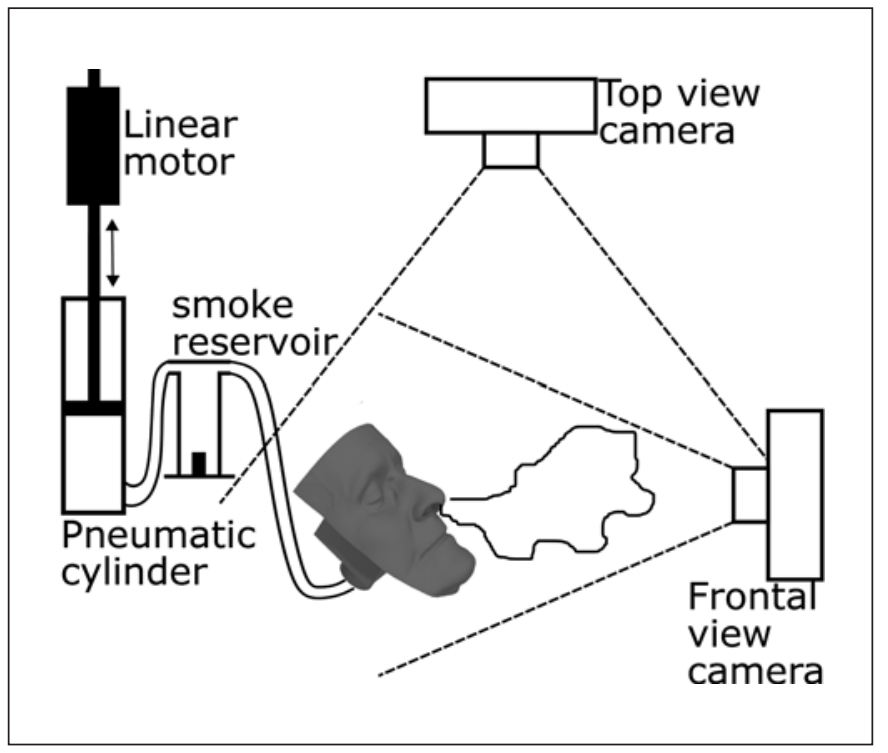

Fig. 1. Schematic overview of the setup. The linear motor drives the pneumatic cylinder, causing movement of air which simulates breathing. Air is drawn through a cylinder with smoke, such that exhaled air from the 3D-printed geometry is visualized. The light reflection from the smoke is recorded by 2 cameras.

travelled by the smoke during $0.5 \mathrm{~s}$ after the first smoke was observed. To average out the influence of slight condition changes, the velocity was estimated for 3 breaths and the mean value and standard deviations were calculated. By assuming a vertical distance of $10 \mathrm{~cm}$ between the patient's nose and neighboring surfaces, and instantaneous terminal vertical velocity, a rough estimate of the dispersion range of large droplets was obtained.

\section{Results}

In Figures 2-7, a series of images are shown for various therapies at different time instants after the start of exhalation (the distance between 2 lines is $10 \mathrm{~cm}$ on the reference plane). The colored regions have a visible concentration of smoke, which can be interpreted as regions with potentially high aerosol concentrations. Remarkably, spread is asymmetric in some cases. Presumable causes for this are the airway structure, the fitting of the therapy setup, and the draft conditions in the laboratory. The maximum spread of high-concentration regions from the nose during the first $2 \mathrm{~s}$ of exhalation is only moderate in unassisted breathing (approximately $30 \mathrm{~cm}$ ), nonrebreathing mask (approximately $25 \mathrm{~cm}$ ), and Venturi mask (approximately $40 \mathrm{~cm}$ ), whereas spread is much larger during NHFT (approximately $70 \mathrm{~cm}$ ), BiPAP (approximately $80 \mathrm{~cm}$ ), and CPAP (approximately $90 \mathrm{~cm}$ ). 

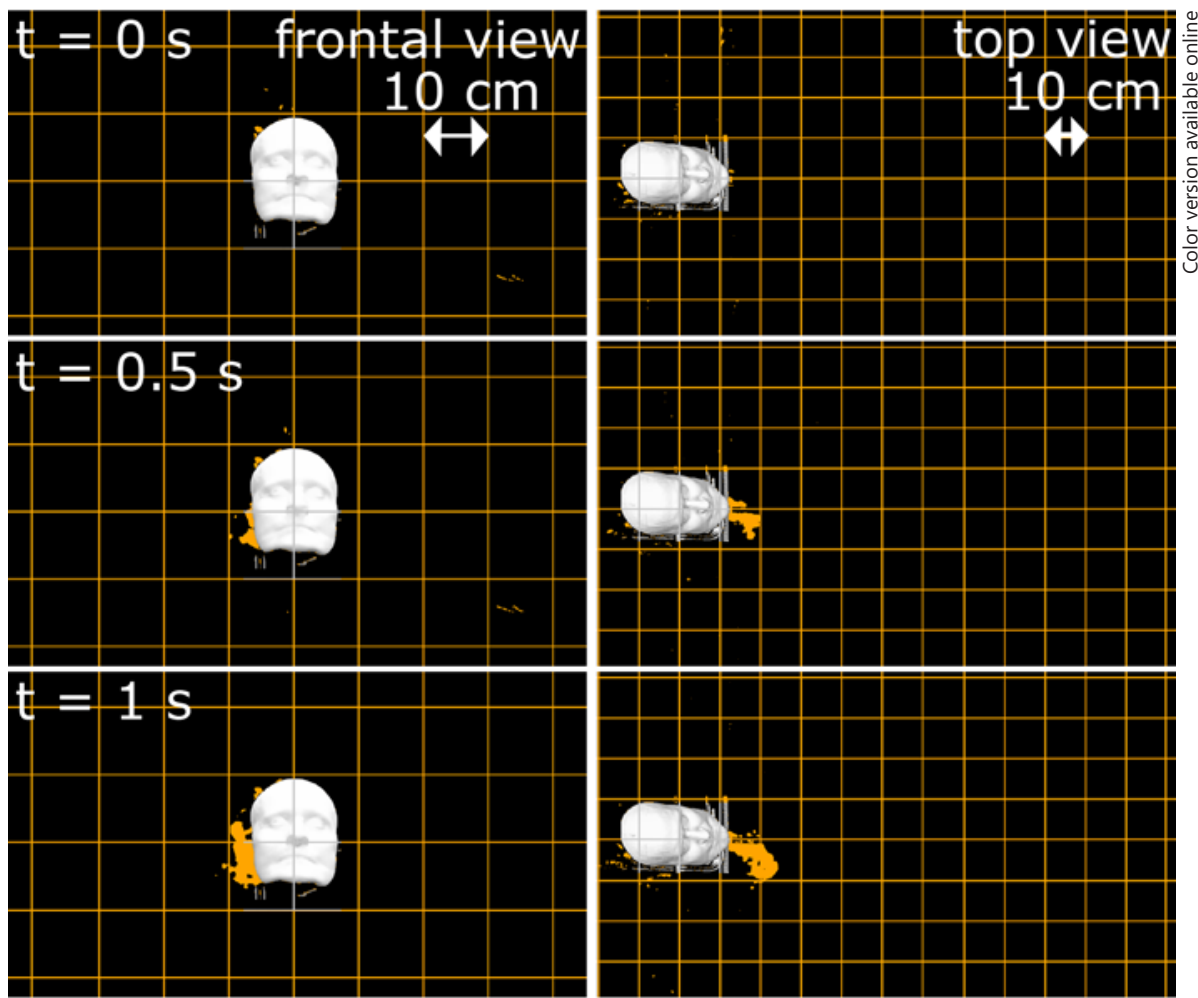

Fig. 2. Unassisted breathing. Regions with high smoke concentration at various times during exhalation.
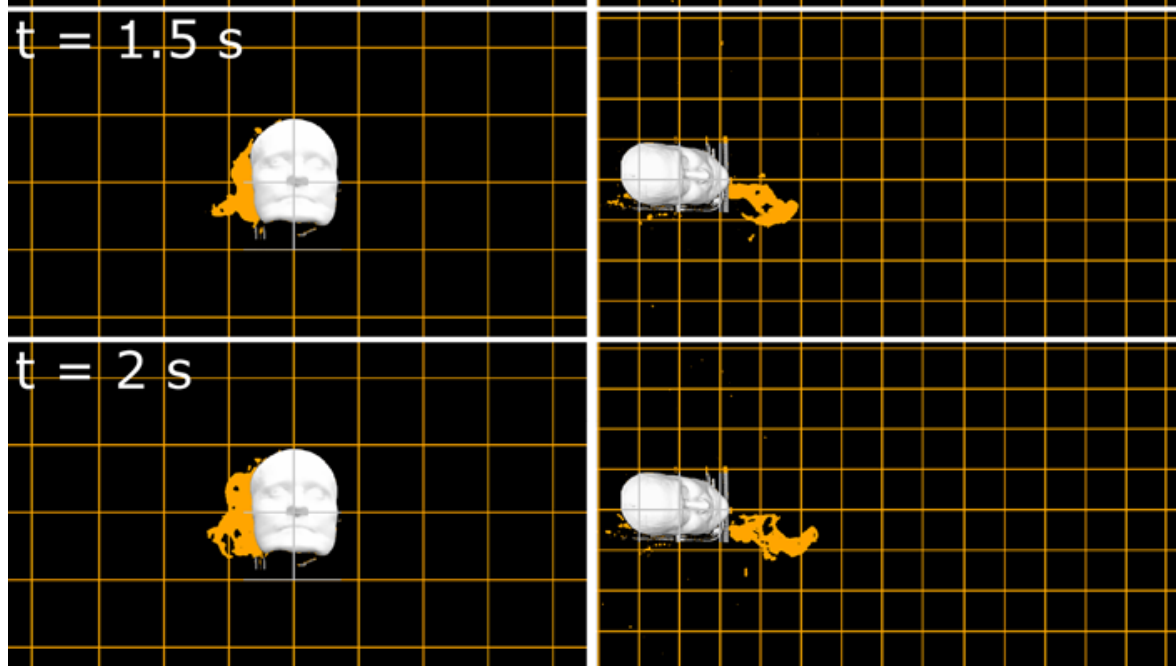

The estimated (initial) jet velocities, averaged over 3 breaths, and the corresponding estimated dispersion range of $100 \mu \mathrm{m}$ droplets are shown in Table 1. Some of these results were presented earlier in Ref. [22]. For unassisted breathing, the estimated droplet dispersion is $<20 \mathrm{~cm}$. Interestingly, this range is even smaller for the Venturi masks, the nebulizer, and the nonrebreathing mask. The nonsurgical face mask has a slightly limiting effect on jet velocity during unassisted breathing. With NHFT, the jets are stronger, and droplets can be spread

Simulation of Virus Transport in Respiratory Support more than twice as far than during spontaneous breathing, depending on the cannula size and the flow rate magnitude. When using a nonsurgical face mask over the NHFT interface, the jet velocity is comparable to unassisted breathing. For CPAP and BiPAP with vented masks, the droplet spread is the highest of all of the tested therapies, with ranges up to 4 times higher than during unassisted breathing. For CPAP and BiPAP with nonvented masks, smoke only escaped through the exhalation port. The postprocessed movies from all 

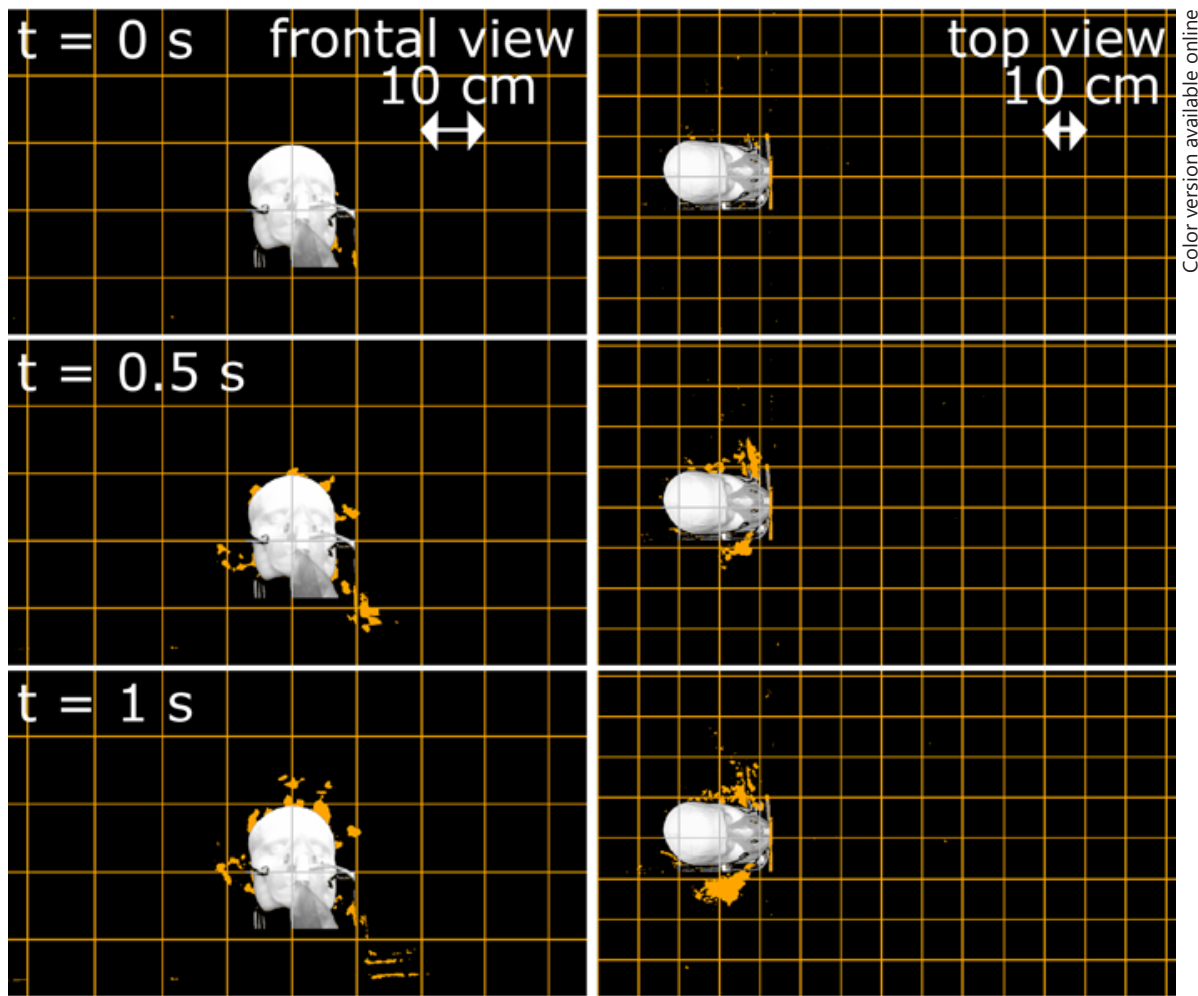

Fig. 3. Nonrebreathing mask, $15 \mathrm{~L} / \mathrm{min}$. Regions with high smoke concentration at various times during exhalation.
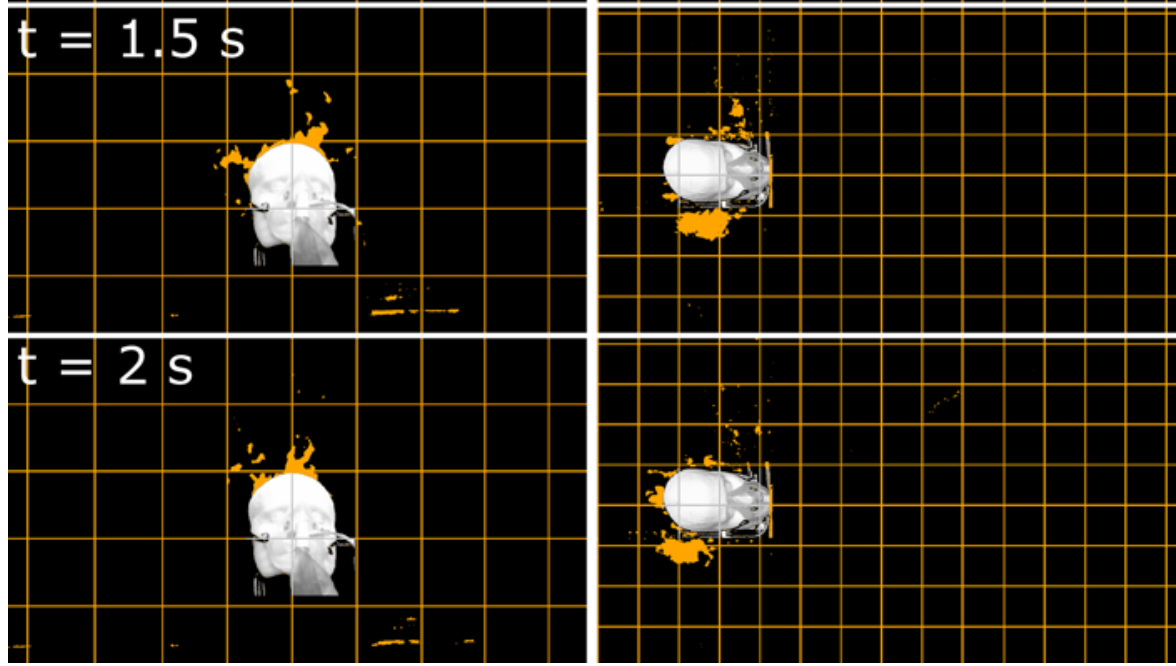

tested therapies and settings can be found in the online supplementary material (for all online suppl. material, see www.karger.com/doi/10.1159/000518735).

\section{Discussion/Conclusion}

To the authors' knowledge, this is the first study to compare the aerodynamics of exhaled air with different noninvasive respiratory support therapies in a single study. Although the direction of the jets is different in the various therapies, the estimated velocities and dispersion ranges of droplets can be well compared. Compared to unassisted breathing, the velocity of the exhaled jet is increased significantly in CPAP, BiPAP, and NHFT, whereas the nebulizer, the nonrebreather mask, and Venturi masks show similar or even lower jet velocities than observed during unassisted breathing. The (nonsurgical) face masks limit the jet velocity and will, in principle, catch the droplets and prevent droplet spread. However, 
Fig. 4. Venturi mask, $\mathrm{FiO}_{2} 0.6,15 \mathrm{~L} / \mathrm{min}$. Regions with high smoke concentration at various times during exhalation.
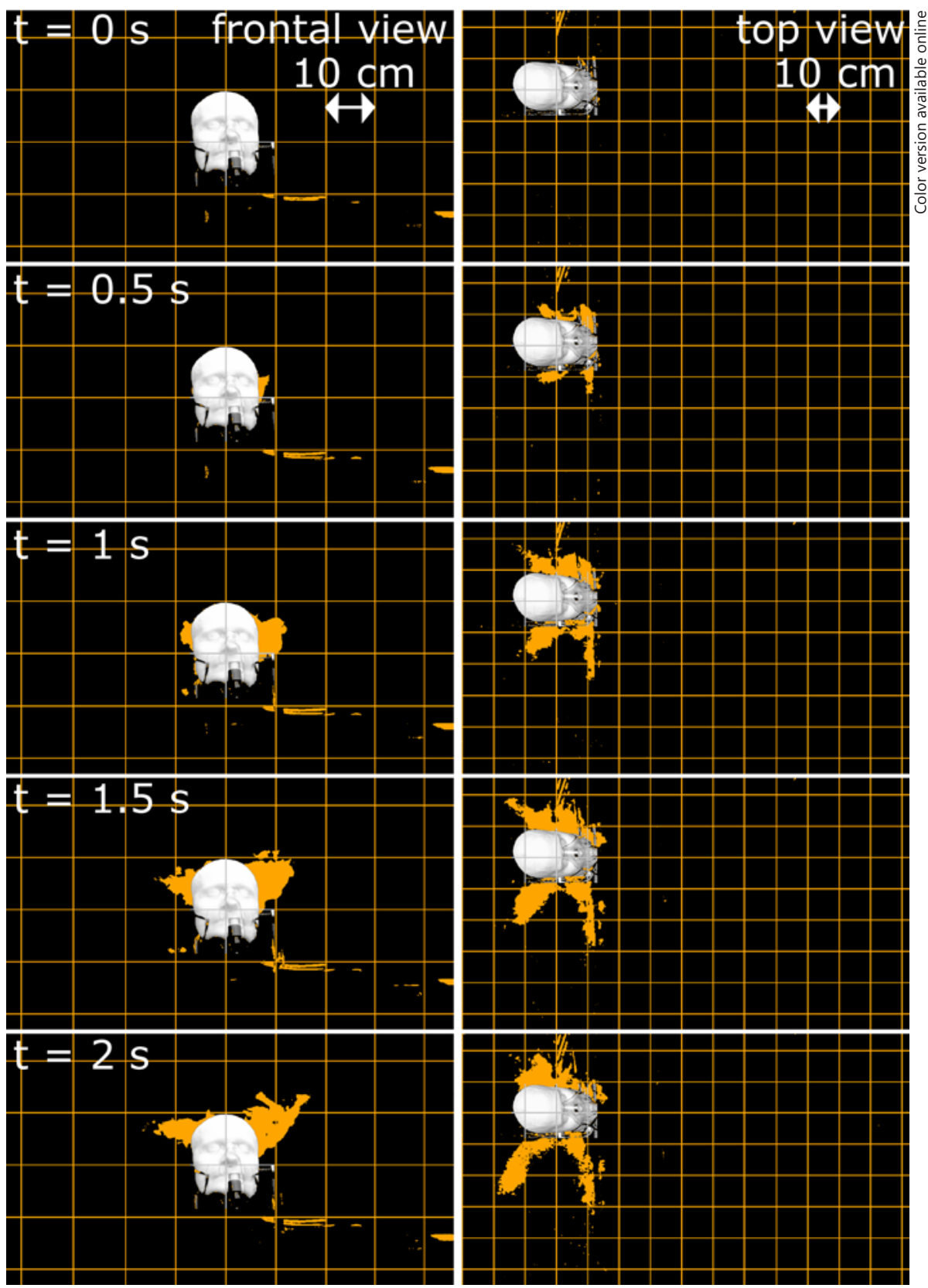

as the smoke demonstrates, there is still a spread of highconcentration aerosol clouds, albeit at a lower velocity.

CPAP and BiPAP with nonvented masks have not been included in Table 1 because air only leaves downstream of the filter location. If a proper filter is used, no droplets are dispersed and therefore estimating the jet velocity is irrelevant. Moreover, a good filter will also prevent aerosol spread, meaning that the risk of both droplet-driven and aerosol-driven virus transmission can be eliminated. Hence, the setup with nonvented masks and a whisper swivel with a filter can be used safely in the hospital. However, this will only be the case if there is no leak between the mask and the face.

Although there is no previous research that compared all noninvasive therapies in a single study, there have been few studies performing smoke visualization experiments on subsets of the therapies studied in our work. Hui et al. [12] compared the exhaled air dispersion during NHFT to CPAP. Maximum air dispersion was only 17.2 $\mathrm{cm}$ during NHFT and $33.2 \mathrm{~cm}$ during CPAP. The report- 

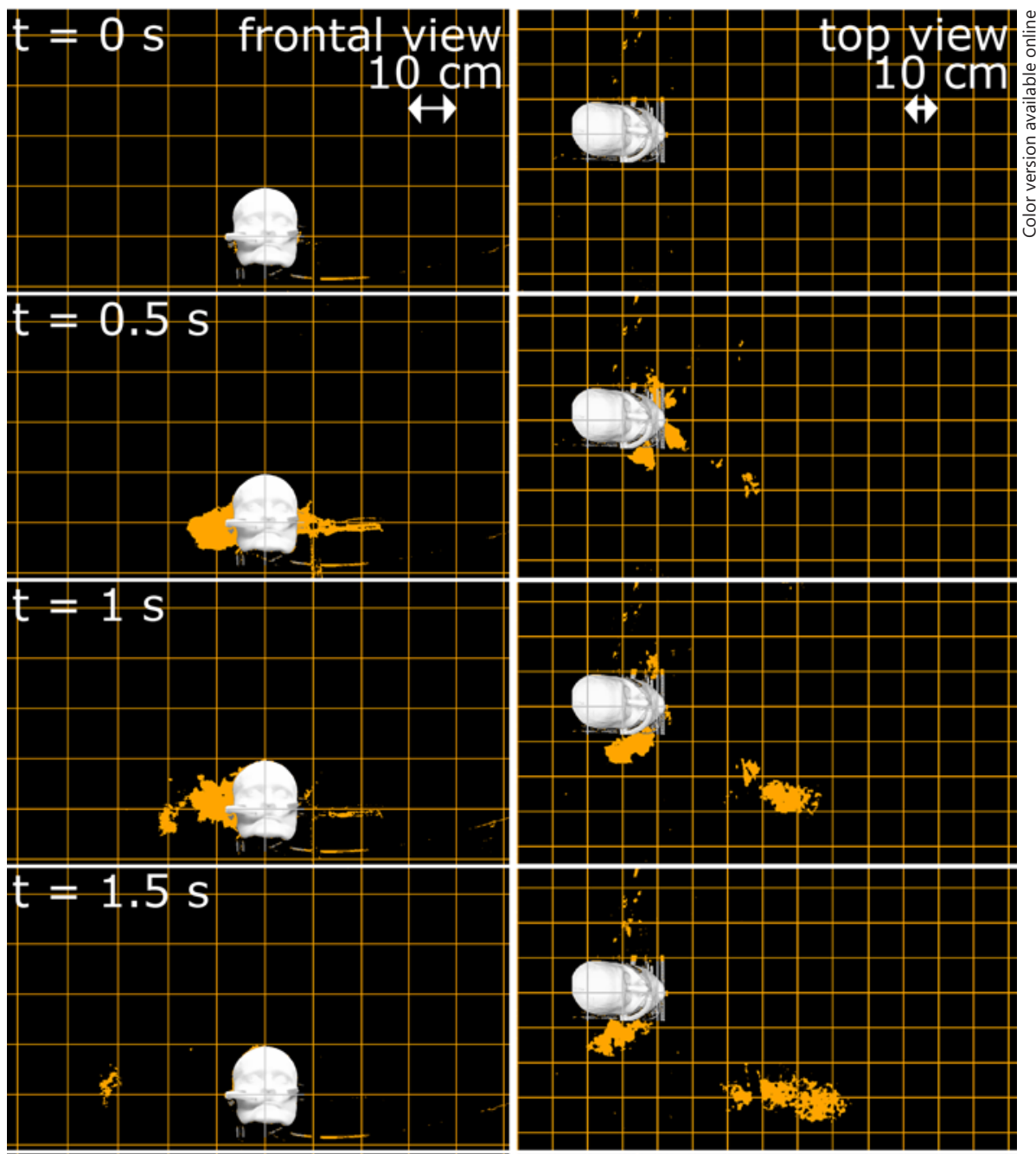

Fig. 5. NHFT, small cannula, $60 \mathrm{~L} / \mathrm{min}$. Regions with high smoke concentration at various times during exhalation. NHFT, nasal high-flow therapy.
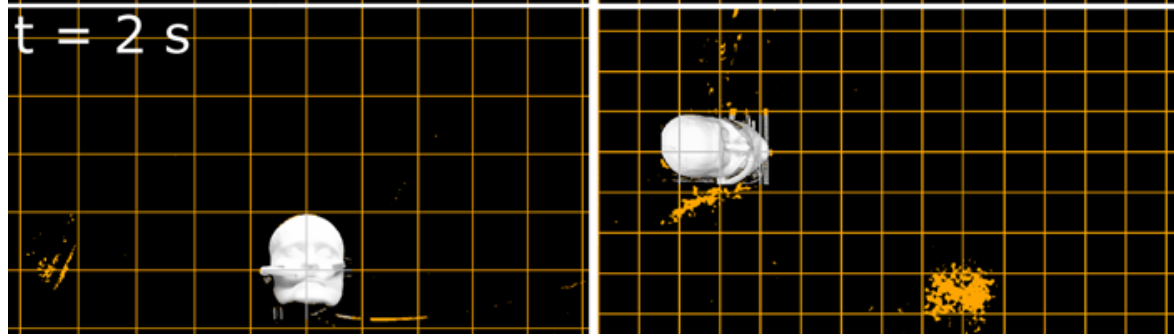

ed distances do not agree with our observations that both therapies showed visible jets with significantly larger extents. Earlier, the same group reported dispersion distances between 40 and $85 \mathrm{~cm}$ during BiPAP and $45 \mathrm{~cm}$ for a nebulizer, both in a negative pressure room, and $33 \mathrm{~cm}$ for a $40 \%$ oxygen Venturi mask in a normal room [11]. Ip et al. [10] reported smoke dispersion distances from an oxygen mask, a nonrebreathing mask, and 2 Venturi masks. Exhaled air dispersion was $39.7 \mathrm{~cm}$ for the $0.4 \mathrm{FiO}_{2}$ Venturi mask and between 24.6 and $34.1 \mathrm{~cm}$ for the non- rebreathing mask (at 10 and $8 \mathrm{~L} / \mathrm{min}$, respectively). These distances appear to agree fairly with the visible smoke spread at end exhalation observed in this study, but it is stressed that the visible extent of smoke is highly dependent on initial smoke concentration, light conditions, and camera sensitivity. In addition, a direct comparison between various studies is hampered due to the differences in setups, settings, and breathing profiles.

Leonard et al. [23] numerically studied the effect of a face mask on the dispersion of aerosols and droplets dur- 

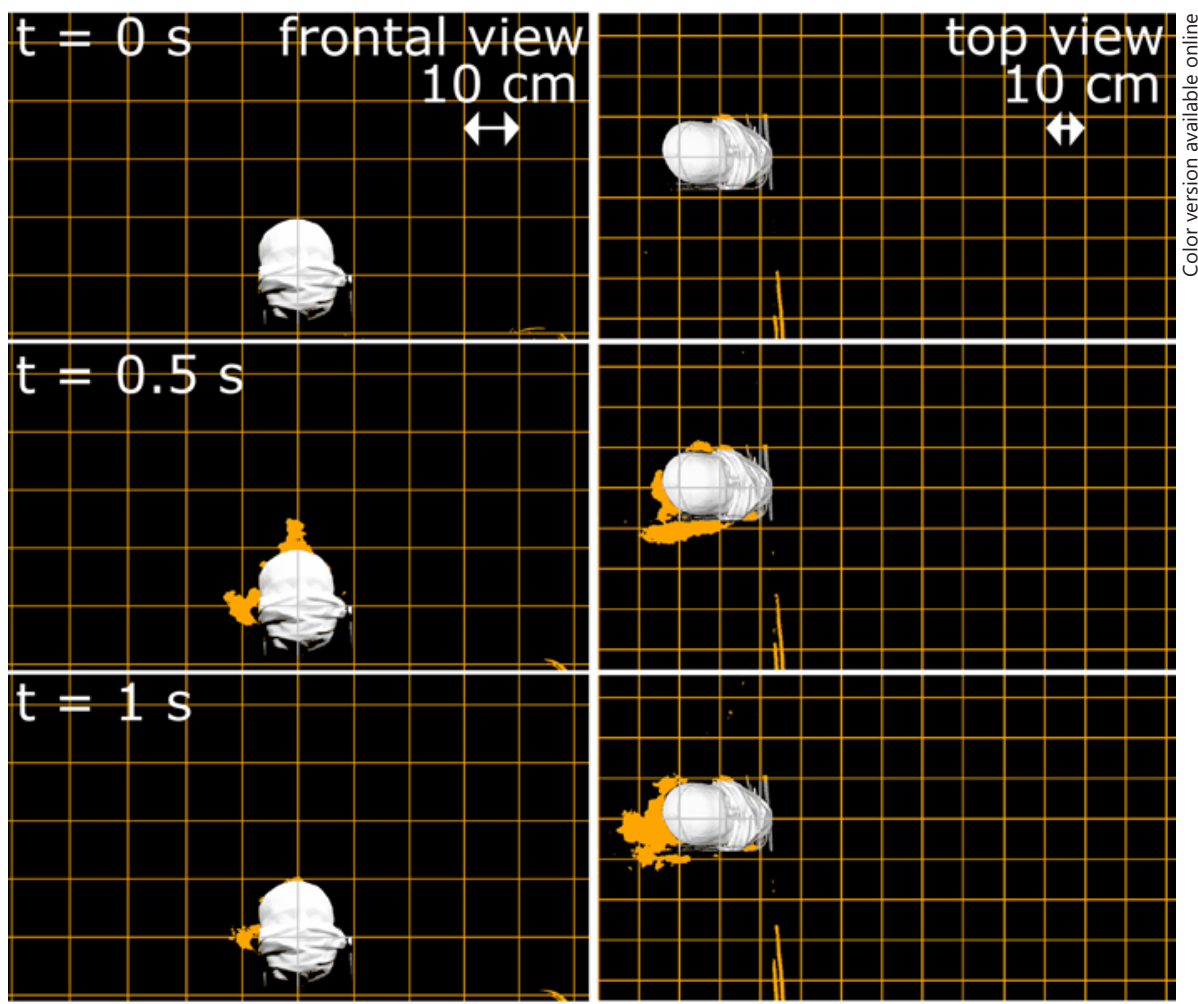

Fig. 6. NHFT, small cannula with a nonsurgical face mask, $60 \mathrm{~L} / \mathrm{min}$. Regions with high smoke concentration at various times during exhalation. NHFT, nasal high-flow therapy.
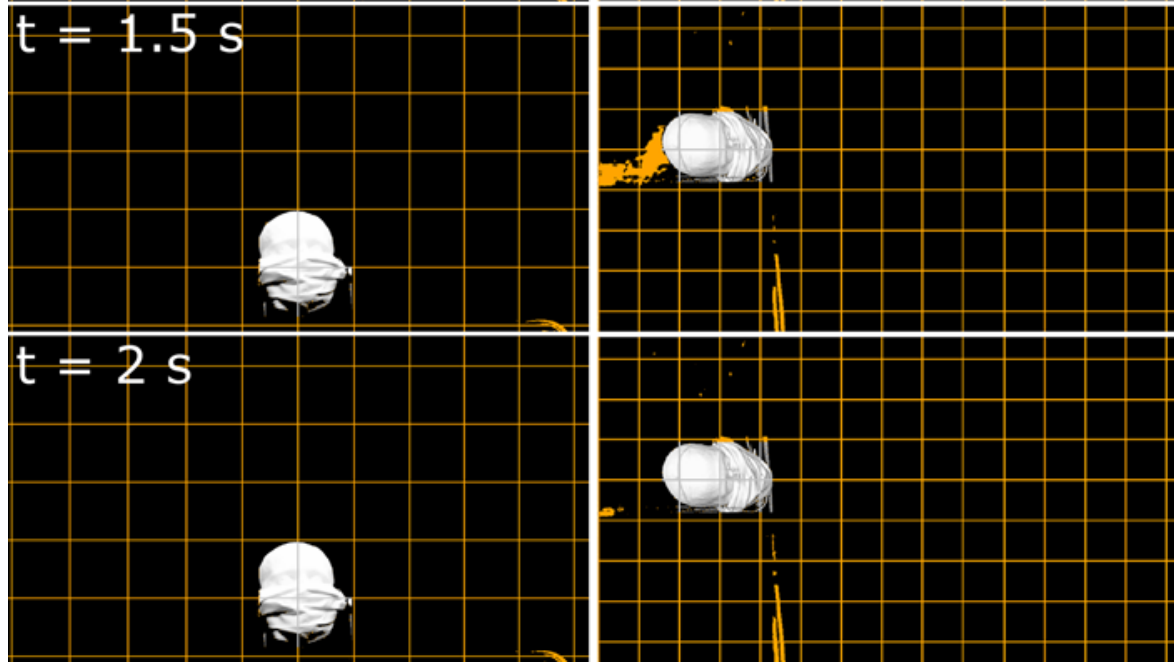

ing NHFT, low-flow oxygen, and unassisted breathing. In all cases, the face mask strongly reduced jet velocities, but particles could still escape through leaks and travel $>1 \mathrm{~m}$.

To interpret the results of smoke-visualization experiments in the light of potential viral spread, it should be noted that the visible extent of the smoke is not representative for the physical extent of exhaled air, since visibility rapidly decreases with time due to mixing with nonexhaled air. The motion of the smoke, however, indicates local jet velocities, which can be used to estimate droplet spread to some extent. The smoke-visualization studies mentioned above did not report jet velocities, so in that respect our study is complementary and provides additional data. For diseases primarily transmitted via droplets, like SARS-CoV-2 [6, 24], the results in Table 1 can close a significant research gap.

The visible extent of smoke does indicate potential high-concentration regions of aerosols. Low-concentration regions are invisible in these experiments, but just like smoke particles, aerosols do not vanish spontaneous- 
Fig. 7. BiPAP with a vented mask, $10 / 5 \mathrm{~cm}$ $\mathrm{H}_{2} \mathrm{O}$. Regions with high smoke concentration at various times during exhalation. BiPAP, bilevel positive airway pressure.
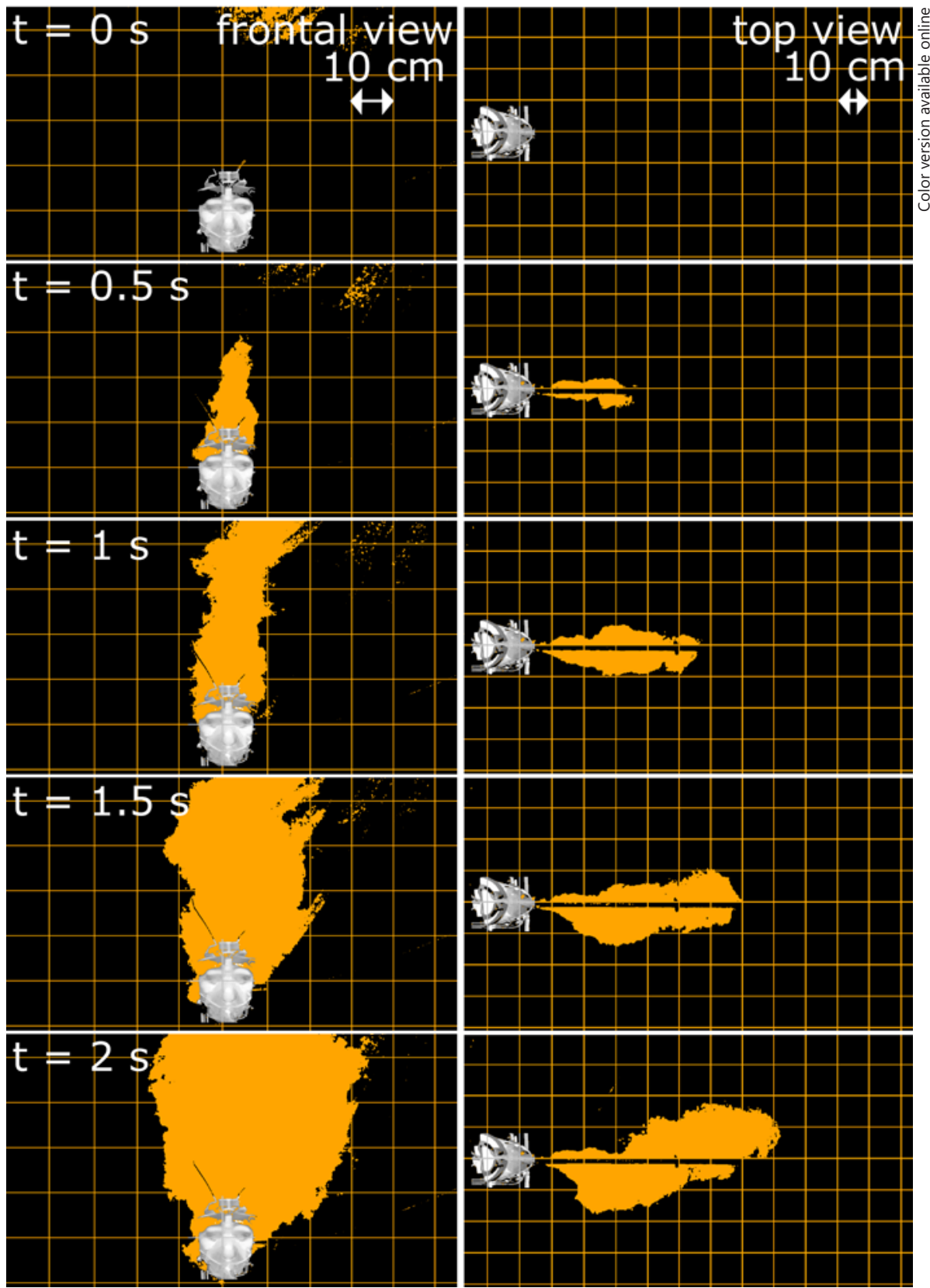

ly, and they will spread around the patient without bound. Since also virus transmission through aerosols is, mainly in poorly ventilated rooms, plausible $[7,15]$, adequate protective measures should be taken.

Coughs are considered to have a major role in the transmission of respiratory viruses [25]. Due to the use of a closed-mouth model, the effect of coughing during ventilatory support could not be studied here. Since the velocities during coughing are higher than during tidal breathing, droplets are likely to be carried further. The dispersion is also extended due to the interaction with and trapping within the turbulent gas cloud emitted by coughs and sneezes $[13,19]$. In a small study with 5 healthy volunteers, cough-generated droplet spread was measured to increase from $2.48 \mathrm{~m}$ without NHFT to 2.91 $\mathrm{m}$ with NHFT (at $60 \mathrm{~L} / \mathrm{min}$ ) [26]. Of note, some studies report mainly small particles being expelled during coughing $[27,28]$, indicating a low risk of droplet-driven virus transmission in comparison to airborne virus transmission. Another study however measured a much 
Table 1. Estimated velocities of the exhalation jet and corresponding estimated dispersion range of $100 \mu \mathrm{m}$ droplets under different conditions (corrected for projection effects where the 3D field of the smoke is not in the 2D planes of the reference lines)

\begin{tabular}{|c|c|c|c|}
\hline Therapy & Settings & $\begin{array}{l}\text { Estimated velocity at } 0.5 \mathrm{~s} \\
\text { after start expiration, } \mathrm{m} / \mathrm{s}\end{array}$ & $\begin{array}{l}\text { Estimated dispersion range } \\
\text { of } 100 \mu \mathrm{m} \text { droplets, } \mathrm{cm}\end{array}$ \\
\hline Unassisted breathing & & $0.41 \pm 0.03$ & $16.3 \pm 1.1$ \\
\hline Unassisted breathing with non-surgical face mask & & $0.32 \pm 0.06$ & $12.7 \pm 2.3$ \\
\hline NHFT, small size cannula & $\begin{array}{l}30 \mathrm{~L} / \mathrm{min} \\
40 \mathrm{~L} / \mathrm{min} \\
50 \mathrm{~L} / \mathrm{min} \\
60 \mathrm{~L} / \mathrm{min}\end{array}$ & $\begin{array}{l}0.68 \pm 0.02 \\
0.71 \pm 0.02 \\
0.80 \pm 0.01 \\
0.85 \pm 0.02\end{array}$ & $\begin{array}{l}27.0 \pm 0.8 \\
28.5 \pm 0.8 \\
32.2 \pm 0.5 \\
34.0 \pm 1.0\end{array}$ \\
\hline NHFT, small size cannula with nonsurgical face mask & $60 \mathrm{~L} / \mathrm{min}$ & $0.47 \pm 0.01$ & $18.7 \pm 0.3$ \\
\hline NHFT, medium size cannula & $\begin{array}{l}30 \mathrm{~L} / \mathrm{min} \\
40 \mathrm{~L} / \mathrm{min} \\
50 \mathrm{~L} / \mathrm{min} \\
60 \mathrm{~L} / \mathrm{min}\end{array}$ & $\begin{array}{l}0.64 \pm 0.01 \\
0.66 \pm 0.05 \\
0.72 \pm 0.09 \\
0.81 \pm 0.03\end{array}$ & $\begin{array}{l}25.7 \pm 0.4 \\
26.4 \pm 2.1 \\
28.8 \pm 3.4 \\
32.5 \pm 1.3\end{array}$ \\
\hline Venturi mask & $\begin{array}{l}\mathrm{FiO}_{2} \text { 0.4, } 10 \mathrm{~L} / \mathrm{min} \\
\mathrm{FiO}_{2} 0.6,15 \mathrm{~L} / \mathrm{min}\end{array}$ & $\begin{array}{l}0.24 \pm 0.03 \\
0.26 \pm 0.03\end{array}$ & $\begin{array}{l}9.7 \pm 1.3 \\
10.4 \pm 1.4 \\
\end{array}$ \\
\hline Nebulizer & $7 \mathrm{~L} / \mathrm{min}$ & $0.32 \pm 0.01$ & $12.9 \pm 0.4$ \\
\hline Nonrebreathing oxygen mask & $15 \mathrm{~L} / \mathrm{min}$ & $0.34 \pm 0.03$ & $13.7 \pm 1.2$ \\
\hline CPAP, vented mask & $\begin{array}{l}5 \mathrm{~cm} \mathrm{H}_{2} \mathrm{O} \\
10 \mathrm{~cm} \mathrm{H}_{2} \mathrm{O} \\
15 \mathrm{~cm} \mathrm{H}_{2} \mathrm{O} \\
20 \mathrm{~cm} \mathrm{H}_{2} \mathrm{O}\end{array}$ & $\begin{array}{l}1.33 \pm 0.04 \\
1.45 \pm 0.03 \\
1.55 \pm 0.03 \\
1.73 \pm 0.02 \\
\end{array}$ & $\begin{array}{l}53.2 \pm 1.6 \\
58.0 \pm 1.4 \\
61.8 \pm 1.4 \\
69.1 \pm 0.7 \\
\end{array}$ \\
\hline
\end{tabular}

Data are presented as mean \pm standard deviation. NHFT, nasal high-flow therapy; CPAP, continuous positive airway pressure; BiPAP, bilevel positive airway pressure.

broader range of particle sizes during coughing [29], so further research is needed to investigate the risk of droplet-driven virus transmission during coughing.

A healthy tidal breathing pattern was simulated in this study, but in practice patients requiring respiratory support will likely have higher in- and expiratory flow rates. A higher expiratory flow rate will lead to higher velocities and consequently increase particle dispersion. It is important to realize that this effect is also modeled by higher flow settings with the same therapy: one may, for example, compare the results of NHFT at $50 \mathrm{~L} / \mathrm{min}$ in this study to those at $30 \mathrm{~L} / \mathrm{min}$ with the expiratory flow rate increased by $20 \mathrm{~L} / \mathrm{min}$ [30]. However, in clinical practice, breathing patterns will be highly variable and also depending on the existence of underlying lung diseases such as COPD. For a qualitative comparison of different ventilatory support methods, it suffices to have the same breathing pattern during all therapies.

Our setup has 3 limitations: (a) initial smoke concentration and light conditions could not be controlled optimally, such that aerosol concentrations could not be quantified; (b) jet velocities were only crudely estimated 
and droplets were assumed to follow simplified, ballistic, trajectories without evaporation; and (c) the exhaled air was unheated except for the induced smoke, neglecting buoyancy effects. Due to (c), jets will rise more in practice, influencing particle trajectories and consequently droplet dispersion. However, the calculated distances already assumed simplified trajectories.

The main advantages of the method of smoke visualization are its ease of use and accessibility, but the method has disadvantages. The manual estimation of the jet velocity may be improved by applying optical flow computation techniques, but to significantly improve the accuracy, it is recommended to use more advanced methods like background-oriented schlieren or particle image velocimetry. The main advantage of background-oriented schlieren is the simplicity of the basic setup, but particle image velocimetry has superior accuracy [31].

Nevertheless, this study aims at gaining awareness of the qualitative differences in droplet and aerosol spreads in various respiratory support methods. All therapies involving high airflows may lead to increased particle dispersion around the patient. It is of concern that infection of caregivers in the COVID-19 pandemic has been significant [6]. Fortunately, infection risks seem to be limited with adequate personal protective equipment (PPE) [32], which, in view of airborne precautions, includes an N95 mask or better [33]. Our data again stress the importance of adequate PPE when using high airflow therapies in any setting.

In summary, exhalation jets during various respiratory support methods on a single patient setup were visualized. During the application of NHFT and CPAP/BiPAP with vented masks, extensive jets with relatively high jet velocities were observed. This indicates an increased spread of droplets and an increased risk of droplet-driven virus transmission. For the Venturi masks, the nonrebreathing mask, and the nebulizer, jet velocities are comparable to or weaker than during unassisted breathing. Aerosols are transported unboundedly in all these unfiltered therapies. From a clinical point of view, this means that it is of vital importance to use adequate protective measures in the use of all noninvasive unfiltered therapies.

The present results indicate that, in clinical practice, caution is needed when applying NHFT, CPAP, and Bi$\mathrm{PAP}$, and caregivers need to be protected with adequate PPE. It appears that no clear preference can be given to one therapy over the other with regard to exhaled air/virus transmission risks. Furthermore, this study confirms that suggested setups to limit spread (surgical mask over
NHFT and use of nonvented masks in CPAP and BiPAP) are relevant and effective in limiting virus particle dispersion. More research is needed to investigate actual infectious virus spread during different situations and therapies.

\section{Statement of Ethics}

An ethics statement was not required for this study type, and no human or animal subjects or materials were used.

\section{Conflict of Interest Statement}

Hebbink reports grants from Vivisol BV, and grants and nonfinancial support from Fisher \& Paykel Ltd., outside the submitted work. Elshof reports grants from Vivisol BV and grants from Fisher \& Paykel Ltd., outside the submitted work. Dr. Duiverman reports grants and personal fees from RESMED Ltd., grants and personal fees from Philips BV, grants from Vivisol BV, and grants from Fisher \& Paykel Ltd., outside the submitted work. The others have nothing to disclose.

\section{Funding Sources}

No funding was given for this study.

\section{Author Contributions}

R.H.J.H., J.E., and R.H. assisted with conception, design, acquisition, analysis, and interpretation of the study; drafted the manuscript; and revised the manuscript. S.W. and W.L. assisted with design and acquisition of the study; and revised the manuscript. M.L. assisted with analysis and interpretation of the study; and revised the manuscript. C.H.V. assisted with design, analysis, and interpretation of the study; and revised the manuscript. M.L.D. assisted with conception, design, analysis, and interpretation of the study; drafted the manuscript; and revised the manuscript. All authors have approved the final manuscript.

\section{Data Availability Statement}

All data generated or analyzed during this study are included in this article or its online supplementary files. Further enquiries can be directed to the corresponding author.
Hebbink/Elshof/Wanrooij/Lette/Lokate/ Venner/Duiverman/Hagmeijer 


\section{References}

1 Wang D, Hu B, Hu C, Zhu F, Liu X, Zhang J, et al. Clinical characteristics of 138 hospitalized patients with 2019 novel coronavirus-infected pneumonia in Wuhan, China. JAMA. 2020 Mar 17;323(11):1061-9.

2 Yang BY, Barnard LM, Emert JM, Drucker C, Schwarcz L, Counts CR, et al. Clinical characteristics of patients with coronavirus disease 2019 (COVID-19) receiving emergency medical services in King County, Washington. JAMA Netw Open. 2020 Jul 8;3(7):e2014549.

3 Cascella M, Rajnik M, Cuomo A, Dulebohn SC, Di Napoli R. Features, evaluation, and treatment of coronavirus (COVID-19). StatPearls. Treasure Island, FL: StatPearls Publishing; 2021 Jul 17.

4 Dondorp AM, Hayat M, Aryal D, Beane A, Schultz MJ. Respiratory support in COVID-19 patients, with a focus on resourcelimited settings. Am J Trop Med Hyg. 2020 Jun 3;102(6):1191-7.

5 Franco C, Facciolongo N, Tonelli R, Dongilli R, Vianello A, Pisani L, et al. Feasibility and clinical impact of out-of-ICU noninvasive respiratory support in patients with COVID19related pneumonia. Eur Respir J. 2020 Nov 5;56(5):2002130.

6 Sommerstein R, Fux CA, Vuichard-Gysin D, Abbas M, Marschall J, Balmelli C, et al. Risk of SARS-CoV-2 transmission by aerosols, the rational use of masks, and protection of healthcare workers from COVID-19. Antimicrob Resist Infect Control. 2020 Jul 6;9(1): 100.

7 Jayaweera M, Perera H, Gunawardana B, Manatunge J. Transmission of COVID-19 virus by droplets and aerosols: a critical review on the unresolved dichotomy. Environ Res. 2020 Sep 1;188:109819.

8 Belser JA, Maines TR, Tumpey TM, Katz JM. Influenza A virus transmission: contributing factors and clinical implications. Expert Rev Mol Med. 2010 Dec 9;12:e39.

9 British Thoracic Society. Guidance for inpatient infection control management of patients receiving acute non-invasive ventilation and long-term ventilation during and beyond COVID-19. 2020.

10 Ip M, Tang JW, Hui DS, Wong AL, Chan MT, Joynt GM, et al. Airflow and droplet spreading around oxygen masks: a simulation mod- el for infection control research. Am J Infect Control. 2007 Dec 1;35(10):684-9.

11 Hui DS, Chan MT, Chow B. Aerosol dispersion during various respiratory therapies: a risk assessment model of nosocomial infection to health care workers. Hong Kong Med J. 2014 Aug;20 Suppl 4(4):9-13.

12 Hui DS, Chow BK, Lo T, Tsang OTY, Ko FW, $\mathrm{Ng}$ SS, et al. Exhaled air dispersion during high-flow nasal cannula therapy versus CPAP via different masks. Eur Respir J. 2019 Apr 11; 53(4).

13 Bourouiba L. Turbulent gas clouds and respiratory pathogen emissions: potential implications for reducing transmission of $\mathrm{CO}$ VID-19. JAMA. 2020 May 12;323(18):1837-8.

14 Prather KA, Wang CC, Schooley RT. Reducing transmission of SARS-CoV-2. Science. 2020 Jun 26;368(6498):1422-4.

15 Somsen GA, van Rijn C, Kooij S, Bem RA, Bonn D. Small droplet aerosols in poorly ventilated spaces and SARS-CoV-2 transmission. Lancet Respir Med. 2020 Jul;8(7):658-9.

16 Simonds AK, Hanak A, Chatwin M, Morrell $\mathrm{M}$, Hall A, Parker $\mathrm{KH}$, et al. Evaluation of droplet dispersion during non-invasive ventilation, oxygen therapy, nebuliser treatment and chest physiotherapy in clinical practice: implications for management of pandemic influenza and other airborne infections. Health Technol Assess. 2010 Oct 11;14(46):131-72.

17 Flagan RC, Seinfeld JH. Fundamentals of air pollution engineering. Englewood Cliffs, New Jersey: Prentice-Hall, Inc.; 1988.

18 Wells WF. On air-borne infection. Study II. Droplets and droplet nuclei. Am J Hyg. 1934; 20:611-8.

19 Bourouiba L, Dehandschoewercker E, Bush JWM. Violent expiratory events: on coughing and sneezing. J. Fluid Mech. 2014 Apr;745: 537-63.

20 van Doremalen N, Bushmaker T, Morris DH, Holbrook MG, Gamble A, Williamson BN, et al. Aerosol and surface stability of SARS$\mathrm{CoV}-2$ as compared with SARS-CoV-1. N Engl J Med. 2020 Apr 16;382(16):1564-7.

21 embodi3D.com. Easily Create 3D Printable Muscle and Skin STL Files from Medical CT Scans. embodi3Dcom. 2016 Oct 30

22 Elshof J, Hebbink RHJ, Duiverman ML, Hagmeijer R. High-flow nasal cannula for CO-
VID-19 patients: risk of bio-aerosol dispersion. Eur Respir J. 2020 Oct 8;56(4):2003004.

23 Leonard S, Atwood CW, Walsh BK, DeBellis RJ, Dungan GC, Strasser W, et al. Preliminary findings on control of dispersion of aerosols and droplets during high-velocity nasal insufflation therapy using a simple surgical mask: implications for the high-flow nasal cannula. Chest. 2020 Sep 1;158(3):1046-9.

24 Centers for Disease Control, and Prevention (CDC). Coronavirus disease 2019 (COVID-19): how COVID-19 spreads. 2020.

25 Dhand R, Li J. Coughs and sneezes: their role in transmission of respiratory viral infections, including SARS-CoV-2. Am J Respir Crit Care Med. 2020 Sep 1;202(5):651-9.

26 Loh NW, Tan Y, Taculod J, Gorospe B, Teope AS, Somani J, et al. The impact of high-flow nasal cannula (HFNC) on coughing distance: implications on its use during the novel coronavirus disease outbreak. Can J Anaesth. 2020 Jul 1;67(7):893-4.

27 Yang S, Lee GW, Chen CM, Wu CC, Yu KP. The size and concentration of droplets generated by coughing in human subjects. J Aerosol Med. 2007 Dec 1;20(4):484-94.

28 Zayas G, Chiang MC, Wong E, MacDonald F, Lange CF, Senthilselvan A, et al. Cough aerosol in healthy participants: fundamental knowledge to optimize droplet-spread infectious respiratory disease management. BMC Pulm Med. 2012 Mar 21;12(1):11.

29 Chao CYH, Wan MP, Morawska L, Johnson GR, Ristovski ZD, Hargreaves M, et al. Characterization of expiration air jets and droplet size distributions immediately at the mouth opening. J Aerosol Sci. 2009 Feb 1;40(2):12233.

30 Kumar H, Spence CJ, Tawhai MH. Modeling the pharyngeal pressure during adult nasal high flow therapy. Respir Physiol Neurobiol. 2015 Dec 1;219:51-7.

31 Raffel M. Background-oriented schlieren (BOS) techniques. Exp Fluids. 2015 Mar 6; 56(3):60.

32 Cook TM. Personal protective equipment during the coronavirus disease (COVID) 2019 pandemic: a narrative review. Anaesthesia. 2020 Jul;75(7):920-7.

33 World Health Organization. Clinical management of COVID-19. 2020
Simulation of Virus Transport in

Respiratory Support
Respiration 2021;100:1196-1207

DOI: $10.1159 / 000518735$ 